\title{
Fabrication and Properties of Polymer Blend Films from Polycondensed Fused Polynuclear Aromatic Resin/Solvent Soluble Nylon System
}

\author{
Kazunari NAwA \\ $R \& D$ Center, Sumitomo Metal Industries, Ltd., \\ 1-8 Fusocho, Amagasaki-shi, Hyogo 660-0891, Japan
}

(Received July 13, 1998)

\begin{abstract}
Novel flexible polymer blend films from polycondensed Fused Polynuclear Aromatic (COPNA) resin/nylon 6 have been reported. ${ }^{1}$ To fabricate polymer blend films using the COPNA resin industrially by solution casting, a solvent soluble nylon was more suitable than nylon 6 for the blend polymer, because the former nylon was soluble in a common solvent. Fabrication and the properties of the new blend films were studied here. The morphology and properties of both B-staged and fully-cured films were compared with those of nylon 6 systems previously reported. 30/70 and 50/50 (COPNA/ solvent soluble nylon) systems were found to exhibit sufficient flexibility and heat resistant property suitable for base materials of flexible printed wiring boards.

KEY WORDS Polycondensed Fused Polynuclear Aromatic Resin / Solvent Soluble Nylon / Polymer Blend / Flexible Film / Solution Cast method
\end{abstract}

In applications of polycondensed fused polynuclear aromatic (COPNA) resin to electrical insulating materials, flexible polymer blend films for base material of flexible printed wiring boards using COPNA resin have been studied. ${ }^{1-3}$ The COPNA resin is known not to exhibit sufficient flexibility similar to an epoxy resin and a phenolic resin when fabricated into thin films, because it forms a three dimensional network structure. There have been great works for giving toughness to epoxy resin, for example, a carboxy-terminated butadiene acrylonitrile (CTBN) modified epoxy resin has been reported. ${ }^{4,5}$ This system has been studied to give bisphenol-A type epoxy resin toughness without losing heat resistant property. To give the COPNA resin sufficient flexibility as the base material for flexible printed wiring boards, polymer blend technology was used here. Polyamide has been selected as a blend polymer with the COPNA resin by reason of high compatibility between amino groups of the polyamide and B-staged COPNA resin. ${ }^{1}$

Nylon 6 was selected as a blend polymer because nylon 6 was a typical polyamide in Japan. Significant fundamental works have been completed and been considered helpful for the new polymer blend technology using the COPNA resin. In the previous work, ${ }^{1}$ the fabrication and properties of the polymer blend films from COPNA resin/nylon 6 were reported as follows: systems of 50/50 and 30/70 (COPNA/nylon 6, wt \%) exhibited sufficient flexibility in practical use, and new systems exhibited higher $T_{\mathrm{g}}$ than the FR-4 graded epoxy resin system. Sufficient flexibility of COPNA resin films was achieved by polymer blend technology.

Flexible polymer blend films for electronics use such as polyimide films are produced by a solution casting as shown in Figure 1.7 This method was used for the following two reasons: film thickness must be precisely the same, and pin-hole free materials must be on the market. Film thickness strongly affects the characteristic impedance of an electric circuit. The characteristic impedance of a strip line circuit, a key property for the electric circuit, depends on the thickness of an insulating layer as follows ${ }^{6}$ :

$$
Z_{0}=\left(60 / \varepsilon^{1 / 2}\right) \ln (5.98 h / \pi(0.8 W+t))
$$

$Z_{0}$ : characteristic impedance,

$\varepsilon$ : dielectric constant of the insulator,

$h$ : thickness of the insulator,

$W$ : width of the electrode,

$t$ : thickness of the electrode

In this equation, film thickness " $h$ " affects the impedance of the circuit directly. Therefore, precisely the same thickness of film is required. The width of the electrode and thickness of the insulator have been becoming smaller with the advance of the density of electronic packages. Therefore, pin-hole free films for insulating materials are required to meet technological trends.

Fabrication of flexible films is described as follows using Figure 1. At first, B-staged resin solution called "dope" is stored in a hopper. The dope is cast onto a rolling drum to form thin layers. The layers are dried by hot air. Semi-dried films are removed from the rolling drum, and are perfectly dried and cured in a high temperature curing zone. When industrial fabrication of flexible polymer blend films has been focused on, the COPNA/nylon 6 system is difficult to use in the solution cast process, since nylon 6 cannot dissolve in a low cost solvent. To solve this problem, a solvent soluble nylon was selected as a blend polymer, because it can dissolve in a low cost solvent such as 1-propanol, 1-butanol, and $N, N$-dimethylformamide (DMF). B-Staged COPNA resin

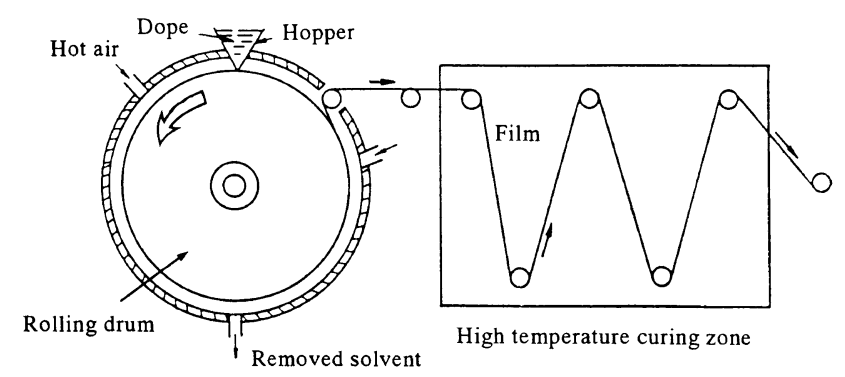

Figure 1. Fabrication of flexible polymer films by solution casting. 
<smiles>CC(C)(O)Cc1ccc(Cc2ccc3ccc([TlH])cc3c2)cc1</smiles>

B-staged COPNA resin

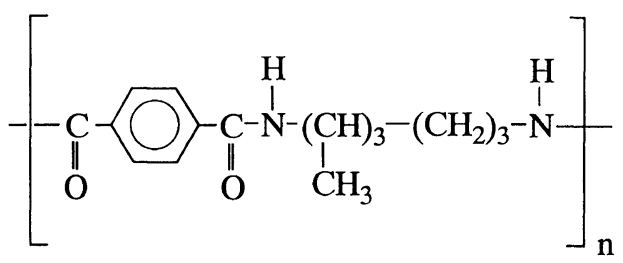

\section{Solvent soluble nylon}

Figure 2. Chemical structures of B-staged COPNA resin and solvent soluble nylon.

Table I. Properties of fully-cured COPNA resin and solvent soluble nylon

\begin{tabular}{lcc}
\hline & COPNA resin & $\begin{array}{c}\text { Solvent soluble } \\
\text { nylon }\end{array}$ \\
\hline Glass transition temperature $/{ }^{\circ} \mathrm{C}$ & 250 & 125 \\
Thermal expansion coefficient/ & 40 & 54 \\
$\quad$ ppm $\mathrm{K}^{-1}$ & & \\
Tensile strength $/ \mathrm{kgf} \mathrm{mm}^{-2}$ & 4.7 & 9.0 \\
Young's modulus $/ \mathrm{kgf} \mathrm{mm}^{-2}$ & 200 & 280 \\
Elongation $/ \%$ & - & $>50$ \\
Dielectric constant $/ 1 \mathrm{MHz}$ & 3.1 & 3.4 \\
Dissipation factor $/ 1 \mathrm{MHz}$ & 0.003 & 0.028 \\
Volume resistivity $/ \Omega \mathrm{cm}$ & $5 \times 10^{15}$ & $>10^{15}$ \\
Water absorption $/ \mathrm{wt} \%$ & 0.37 & 2.0 \\
\hline
\end{tabular}

dissolves in dichloromethane, tetrahydrofuran, methylethylketone, dioxane, DMF, and isophrone. ${ }^{1-3}$ Therefore, DMF can be used as a common solvent to fabricate flexible polymer blend films from COPNA resin/solvent soluble nylon system in a conventional solution casting. For industrial production, fabrication and properties of the polymer blend films from the COPNA/solvent soluble nylon system have been studied. Here, the morphology, thermal properties, physical and electrical properties of the B-staged and fully-cured polymer blend films were mainly studied.

\section{EXPERIMENTAL}

\section{Samples}

B-Staged COPNA resin whose chemical structure is given in Figure 2, was from Sumikin Chemicals (SKRNM). The molecular weights of the resin was $M_{n}=$ $9.5 \times 10^{2}, M_{w}=2.6 \times 10^{3}$, and $M_{w} / M_{n}=2.7$. Synthesis and characterization of the COPNA resin are described in previous papers. ${ }^{8-10}$ Solvent soluble nylon, whose chemical structure is shown in Figure 2, was from DaicelHuls Ltd. (Trogamid 5000). The molecular weight of the solvent soluble nylon was $M_{n}=2.0 \times 10^{4}, M_{w}=3.9 \times 10^{4}$, and $M_{w} / M_{n}=2.0$. The properties of the fully-cured COPNA resin and solvent soluble nylon are shown in Table I. DMF was from Kishida Chemicals.
Fabrication of B-Staged and Fully-Cured Polymer Blend Films

B-Staged COPNA resin solution in DMF was prepared at $20 \mathrm{wt} \%$. Solvent soluble nylon solution in DMF was prepared at $20 \mathrm{wt} \%$. These solutions were mixed in a weight ratio of COPNA/nylon $=30 / 70,50 / 50$, and 70/30. The blend solutions were cast into petri dishes maintained at $80^{\circ} \mathrm{C}$ to remove the solvent. The semi-dried blend films removed from the support were further dried in a vacuum desiccator for more than $48 \mathrm{~h}$ to completely remove the solvents.

Fully-cured polymer blend films were obtained by curing in air at $180^{\circ} \mathrm{C}$ for $60 \mathrm{~min}$. followed by $230^{\circ} \mathrm{C}$ for $60 \mathrm{~min}$. The film thickness of the fully-cured polymer blend films was from 78 to $100 \mu \mathrm{m}$.

\section{Measurements}

Morphological Analysis.

Morphological analysis of the blend films was carried out by a Hitachi $\mathrm{H}-4100 \mathrm{FA}$ transmission electron microscope at $100 \mathrm{kV}$ voltage. Ultra thin film samples were obtained by an ultra-microtome with glass knives. The films were dyed with tungstophosphoric acid.

Measurement of Thermal, Electrical, and Physical Properties of Films.

Thermal properties of the blend films were measured by differential scanning calorimetry (DSC) and thermal mechanical analysis (TMA). DSC and TMA heating rates were $10^{\circ} \mathrm{C} \mathrm{min}^{-1}$ in nitrogen and $5^{\circ} \mathrm{C} \mathrm{min}^{-1}$ in air, respectively. DSC and TMA used were Mac Science DSC 3200 and TMA 4000, respectively.

Physical and other properties of fully-cured films were measured according to ASTM D-882. Electrical properties of the films were measured according to ASTM D-150 and IPC-S-100. Tensile strength was measured with a Shimadu AGS-50ND. The impedance analyzer and high resistance meter were Hewlett-Packard HP4194A and 4329A, respectively.

\section{RESULTS AND DISCUSSION}

\section{Thermal Analysis of B-Staged Polymer Blend Films}

To analyze the thermal properties of B-staged polymer blend films from COPNA resin/solvent soluble nylon consisting of three different nylon fractions, differential scanning calorimetry (DSC) was carried out. Figure 3 shows DSC curves of the systems. DSC curves of the COPNA resin and nylon are given for comparison. In Figure 3(a), B-staged COPNA resin exhibited $T_{\mathrm{m}}$ at $121^{\circ} \mathrm{C}$, and exothermic behavior owing to a cross-linking reaction in the temperature range between $140^{\circ} \mathrm{C}$ and $230^{\circ} \mathrm{C}$. In Figure $3(\mathrm{e}), T_{\mathrm{g}}$ of the solvent soluble nylon was observed at $125^{\circ} \mathrm{C}$, and endothermic behavior was observed at 180 to $205^{\circ} \mathrm{C}$ with a peak temperature at $191^{\circ} \mathrm{C}$. This endothermic behavior was considered due to the melt of partially crystallized nylon molecules in the solvent soluble nylon homo-polymer. ${ }^{11}$ For polymer blend systems (Figure 3(b),(c), and (d)), endothermic behavior from the melt of the partially crystallized nylon was observed at $160^{\circ} \mathrm{C}$ and $205^{\circ} \mathrm{C}$, while this temperature shifted to lower temperature than that of the nylon $100 \%$ system. Exothermic behavior owing to a cross-linking reaction of the COPNA resin was observed at 220 to 


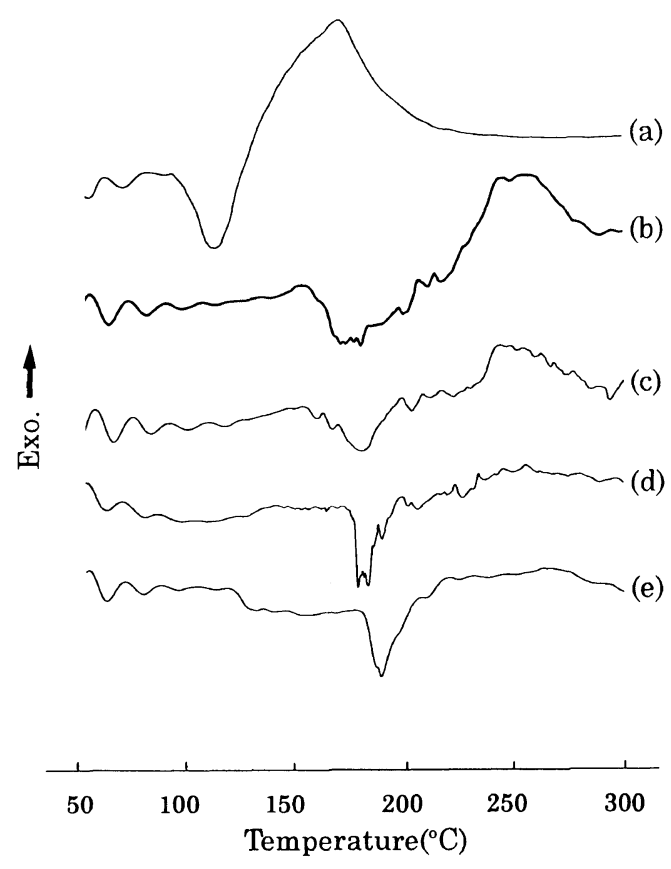

Figure 3. DSC curves of B-staged polymer blend films from COPNA/solvent soluble nylon system whose fractions are (a) $100 / 0$, (b) 70/30, (c) 50/50, (d) 30/70, and (e) 0/100 (COPNA/nylon). Raising speed of temperature is $10^{\circ} \mathrm{C} \mathrm{min}-1$.

$290^{\circ} \mathrm{C}$. This range shifted to higher temperature than that of the COPNA resin $100 \%$ system. Total calories of the cross-linking reaction depended on the fraction of the COPNA resin, and decreased when the COPNA fraction decreased.

Typical thermal properties of the blends: temperature shift of endothermic behavior from the melt of the crystallized nylon, and that of the exothermic behavior from the cross-linking reaction of the COPNA resin, were also observed in the COPNA resin/nylon 6 system as shown in the previous paper. ${ }^{1}$ Both phenomena may be due to the correlation between COPNA and nylon molecules. The interface of the COPNA/nylon 6 system was previously analyzed by spectroscopic methods such as FT-IR, ${ }^{13} \mathrm{C}$ NMR, and ${ }^{15} \mathrm{~N}$ NMR. ${ }^{2}$ In that paper, a graft reaction between amide combinations of the nylon 6 and benzyl-typed cations of the B-staged COPNA resin was reported. In the case of the former phenomenon, it is due to the unstability of the crystalline state of the nylon. The nylon molecules are partially grafted by the COPNA resin. Therefore, crystallization of the nylon is restrained and thermodynamically unstable. For the latter phenomenon, it is due to the reaction mechanism of the polymer blend system. The reaction mechanism of the polymer blend from the COPNA/nylon 6 previously reported ${ }^{3}$ consisted of two steps: graft reaction between amide combinations of the nylon 6 and benzyltyped cations of the B-staged COPNA resin below $80^{\circ} \mathrm{C}$, and a cross-linking reaction of the COPNA resin over $100^{\circ} \mathrm{C}$. The cross-linking reaction thus occurs after the graft reaction. In this case, some benzyl-typed cations are consumed by the graft reaction with the amide groups of the nylon, so the cross-linking reaction is comparatively harder to occur than the COPNA homo-polymer. Therefore, the temperature shift of the exothermic behavior was observed.
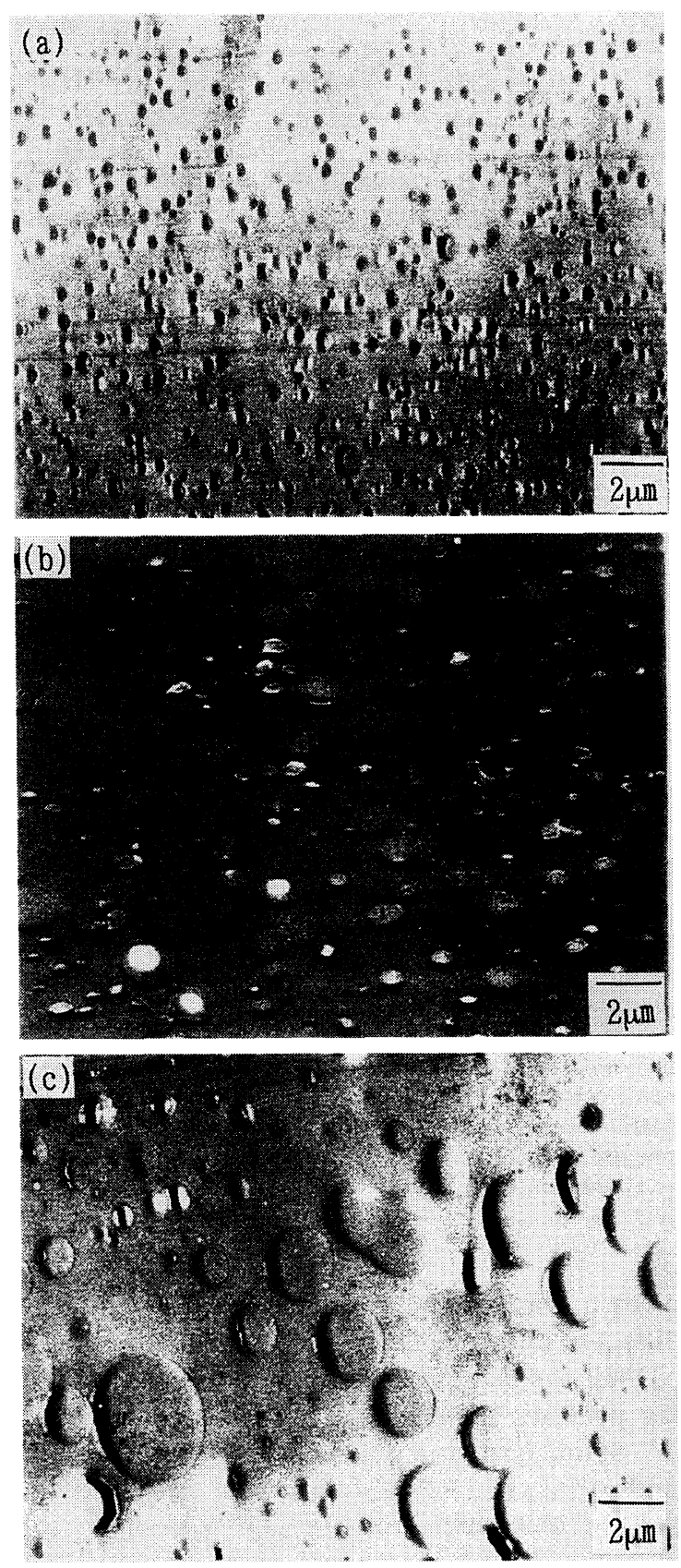

Figure 4. TEM images of B-staged polymer blend films from COPNA/solvent soluble nylon system whose fractions are (a)30/70, (b) 50/50, and (c) 70/30 (COPNA/nylon).

The exothermic behavior of the COPNA/solvent soluble nylon system seems more obvious than that of the COPNA/nylon 6 system. The reason has not been clear, but it might be differences in degree of the graft reaction. The solvent soluble nylon contains aromatic rings as shown in Figure 2. The solvent soluble nylon molecule has so large a free volume than the nylon 6 that the graft reaction is hard to occur compared with the nylon 6 system. In this case, the number of benzyl cations left in the COPNA/solvent soluble nylon system is more than that of the COPNA/nylon 6 system. Therefore, the exothermic peak of the solvent soluble nylon system seems more obvious than that of the nylon 6 system. 


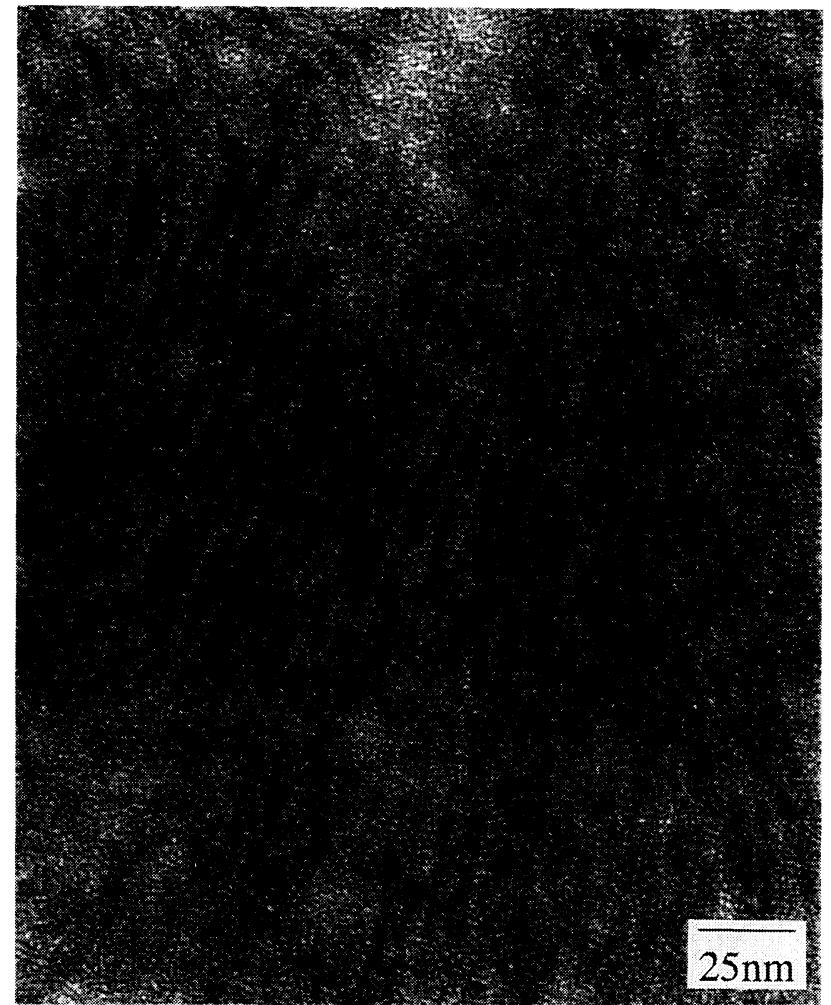

Figure 5. TEM images of B-staged polymer blend from COPNA nylon 6 system at high magnification.

\section{Morphological Analysis of B-Staged Polymer Blend Films}

Morphological analysis of B-staged polymer blend films from COPNA resin/solvent soluble nylon was carried out by TEM to discuss compatibility between the COPNA resin and solvent soluble nylon. Figure 4 shows TEM images of the B-staged polymer blend films. It is difficult to obtain an obvious contrast between the COPNA resin and amorphous nylon by a tungstophosphoric acid dying method used for the COPNA/nylon 6 system, because these polymers are not easily dyed by the acid. From a preparatory experiment, the COPNA resin was dyed to a more grayish color than the solvent soluble nylon. Therefore, the morphology of the new polymer blend may consist of a grayish-colored COPNA domain and white-colored solvent soluble nylon domain. In Figure 4, the entire fraction system exhibited a structure similar to the "sea-island like structure," where the COPNA resin was an island like domain and solvent soluble nylon was a continuous phase. The diameter of the COPNA domain of 30/70 (COPNA/nylon) system was less than $1 \mu \mathrm{m}$ (Figure $4(\mathrm{a})$ ), while that of $70 / 30$ system was partly more than $3 \mu \mathrm{m}$ (Figure $4(\mathrm{c})$ ). The diameter of the COPNA resin became large with increase in the COPNA fraction. Therefore, compatibility between the COPNA and solvent soluble nylon was comparatively poor in the high COPNA fraction system.

For the COPNA resin/nylon 6 system as shown in the previous work, ${ }^{1}$ the fraction systems exhibited structures similar to each other. Spherulites owing to the lamellar structure of the crystallized nylon 6 were observed in the COPNA matrix. However, when the morphology of the COPNA/nylon 6 system is compared with that of the COPNA/solvent soluble nylon system at the same COPNA fraction, quite different and interesting charac-
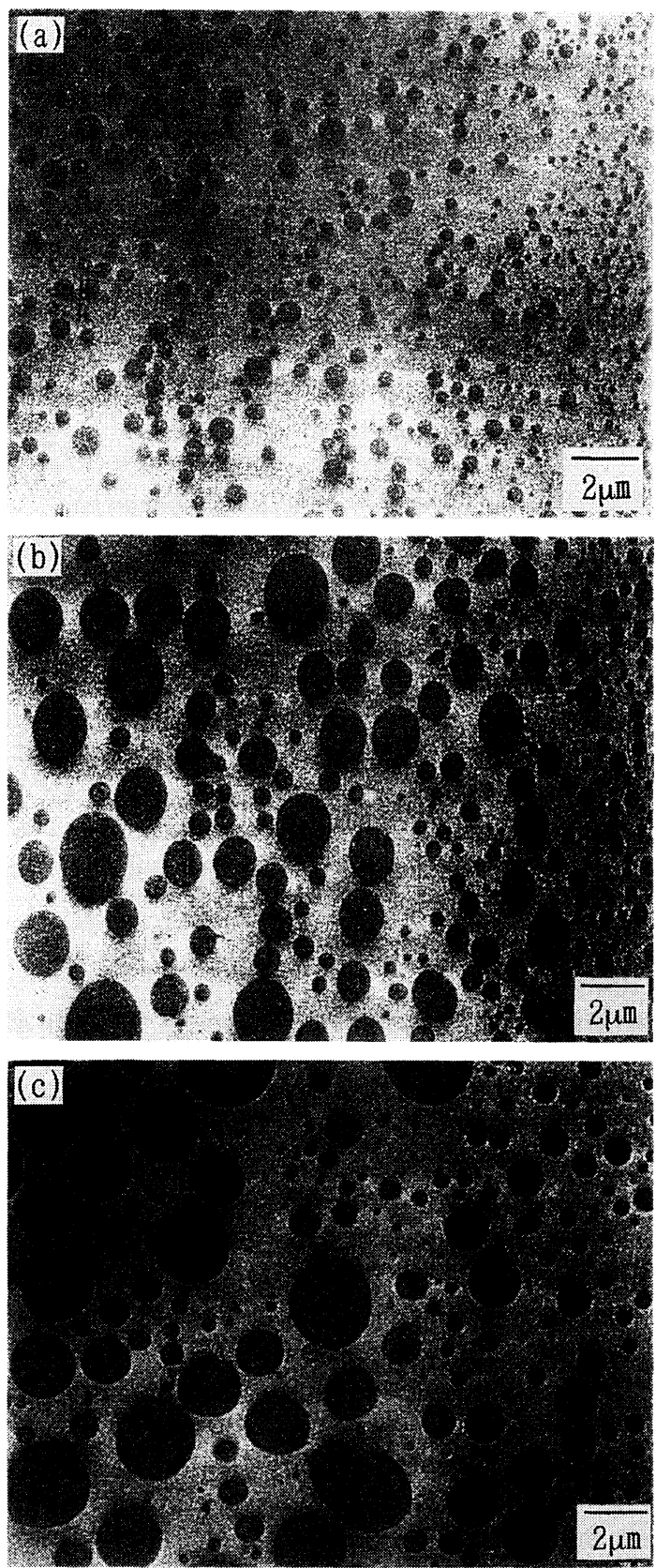

Figure 6. TEM images of fully-cured polymer blend films from COPNA/solvent soluble nylon system whose fractions are (a) $30 / 70$, (b) 50/50, and (c) 70/30 (COPNA/nylon).

teristics are seen in size and structure of the COPNA domain. In the case of the nylon 6 system, the lamellar structure of the nylon 6 spreads into the COPNA matrix and the width of the lamellar structure is $5-10 \mathrm{~nm}$ as shown in Figure 5 measured by the high magnification TEM analysis. For the solvent soluble nylon system, COPNA domain is dispersed as particles in the nylon matrix, and domain size is less than $1 \mu \mathrm{m}$ to more than $3 \mu \mathrm{m}$. The compatibility of the B-staged COPNA resin with nylon 6 should thus be higher than that with the solvent soluble nylon.

\section{Morphological Analysis of Fully-Cured Polymer Blend Films}

Figure 6 shows TEM images of the fully-cured COPNA resin/solvent soluble nylon system. In Figure 6, each 
Table II. Properties of fully-cured polymer blend films from COPNA/solvent soluble nylon system

\begin{tabular}{|c|c|c|c|c|c|}
\hline System (COPNA/nylon) & $0 / 100$ & $30 / 70$ & $50 / 50$ & $70 / 30$ & $100 / 0$ \\
\hline Film thickness $/ \mu \mathrm{m}$ & 50 & 80 & 78 & 100 & 50 \\
\hline Flexibility $^{\mathrm{a}}$ & No cracks & No cracks & No cracks & Cracks & Cracks \\
\hline Glass transition temperature $/{ }^{\circ} \mathrm{C}$ & 125 & 133 & 140 & 155 & 250 \\
\hline Thermal expansion coefficient/ppm K $\mathrm{K}^{-1}$ & 54 & 65 & 49 & 40 & 40 \\
\hline Tensile strength $/ \mathrm{kgf} \mathrm{mm}^{-2}$ & 9.0 & 5.7 & 6.5 & 4.3 & 4.7 \\
\hline Young's modulus $/ \mathrm{kgf} \mathrm{mm}^{-2}$ & 280 & 211 & 238 & 195 & 200 \\
\hline Dielectric constant/1 MHz & 3.4 & 3.3 & 3.3 & 3.2 & 3.1 \\
\hline Dissipation factor $/ 1 \mathrm{MHz}$ & 0.028 & 0.015 & 0.012 & 0.011 & 0.003 \\
\hline Volume resistivity $/ \Omega \mathrm{cm}$ & $>10^{15}$ & $>10^{15}$ & $>10^{15}$ & $>10^{15}$ & $5 \times 10^{15}$ \\
\hline Water absorption/wt $\%$ & 2.0 & 1.1 & 0.8 & 0.5 & 0.37 \\
\hline
\end{tabular}

${ }^{a}$ Evaluated by the folding test up to 180 degrees.

system maintains a phase separated structure similar to its own B-staged structure and exhibits a typical sea-island like structure. The diameter of the COPNA domain was approximately the same as for the B-staged systems. The compatibility between COPNA and the solvent soluble nylon was poor when the COPNA fraction increased. From morphological analysis of the fully-cured films, the properties of the polymer blends appeared to obey the additive law.

\section{Properties of Fully-Cured Polymer Blend Films}

Table II shows physical, thermal, electrical, and other properties of the polymer blend films from COPNA resin/solvent soluble nylon system. In this section, flexibility is primarily discussed. Flexibility of the films was evaluated by folding tests up to 180 degrees. The tests were repeated for 100 cycles. Films, exhibiting no cracks in the folded region after the folding tests, met the requirements of base materials for flexible printed wiring boards in practical use. The systems whose fractions were 30/70 and 50/50 (COPNA/nylon) did not exhibit cracks in the folded region, while the $70 / 30$ system exhibited brittleness. Therefore, the $30 / 70$ and $50 / 50$ systems have sufficient flexibility in practical use. Sufficient flexibility of the $30 / 70$ and $50 / 50$ systems of the polymer blend is supported by morphological analysis discussed in the previous section as shown in Figure 6. Compatibility of the previous two systems was high, because the domain size of the COPNA was so small as less than $2 \mu \mathrm{m}$. The domain size of the COPNA in $70 / 30$ system was comparatively large and partially more than $3 \mu \mathrm{m}$. Therefore, the system may exhibit brittleness inside the COPNA domain during the 180 degrees folding test.

Most of the physical, thermal and electrical properties of polymer blend films from COPNA/amorphous nylon system were approximately controlled by the additive law. For thermal properties, systems of the polymer blends exhibited glass transition temperature $\left(T_{\mathrm{g}}\right)$ between $133^{\circ} \mathrm{C}$ and $155^{\circ} \mathrm{C}$, and the $T_{\mathrm{g}}$ increased with the COPNA fraction. $T_{\mathrm{g}} \mathrm{s}$ of the polymer blends were higher than that of the FR-4 graded epoxy resin system $\left(120^{\circ} \mathrm{C}\right)$. Therefore, $T_{\mathrm{g}} \mathrm{s}$ of the blends were sufficient for the flexible films of the flexible printed wiring boards. Coefficients of thermal expansion (CTE) of the systems were between $40 \mathrm{ppm}$ and $65 \mathrm{ppm}$, and CTEs decreased with increase of COPNA fraction. Tensile strength of the polymer blend films was between 4.3 and $5.7 \mathrm{kgf} \mathrm{mm}^{-2}$, and dielectric constants of the blends were between 3.2 and 3.3 , and tensile strength and dielectric constants decreased with increase in the COPNA fraction. For water absorption, it was between $0.5 \mathrm{wt} \%$ and $1.1 \mathrm{wt} \%$, and decreased with increase in the COPNA fraction.

The additive properties of the polymer blend films are consistent with the morphology of fully-cured states. In the TEM images of the fully-cured blend films shown in Figure 6, systems exhibited similar morphology as a sea-island like structure, and domain size of the COPNA increased with the COPNA fraction. Physical, electrical and thermal properties are thus considered to depend on the COPNA fraction. Based on the properties of the polymer blends from COPNA/solvent soluble nylon system, 30/70 and 50/50(COPNA/nylon) systems exhibit both sufficient flexibility and heat-resistant property. These two systems are thus suitable for flexible films of the flexible printed wiring boards.

\section{CONCLUSION}

To fabricate polymer blend films industrially using COPNA resin by solution casting, solvent soluble nylon was selected as a blend polymer because the nylon easily dissolved in DMF. Fabrication and properties of the blends from COPNA resin/solvent soluble nylon system were studied. Morphologies of the B-staged and fully-cured films were similar, and exhibited typical "sea-island like structures." COPNA and nylon were observed as an island-like domain and as a continuous phase, respectively. Physical and thermal properties of the blends were controlled by the additive law. The $30 / 70$ and 50/50 systems exhibited both sufficient flexibility and heat-resistant property in practical use. Therefore, these two systems are suitable as base films of the flexible printed wiring boards.

\section{REFERENCES}

1. K. Nawa, J. Appl. Polym. Sci., 61, 1737 (1996).

2. K. Nawa and H. Kanata, J. Appl. Polym. Sci., 63, 549 (1997).

3. K. Nawa, Jpn. J. Polym. Sci. and Technol., 54, 255 (1997).

4. M. Ochi, M. Yamauchi, O. Kiyohara, and T. Tagami, J. Adhesion Sci. Technol., 9, 1559 (1995).

5. M. Ochi, M. Uno, K. Mimura, T. Kamoto, T. Tagami, and S. Kiyohara, Jpn. J. Polym. Sci. and Technol., 49, 953 (1992).

6. M. Nakagawa, "Design of Printed Wiring Boards," Nikkan Kougyo Newspaper Press, Tokyo, 1989. 
Blends of COPNA and Nylon

7. S. Okiyama, "Plastic Films," Gihoudou Press, Tokyo, 1995.

8. K. Nawa and M. Ohkita, IEEE Trans. on Components, Packaging, and Manufacturing Technology, B18, 4 (1995).

9. K. Nawa, S. Ueda, and H. Watanabe, IEEE Trans. on Components, Packaging, and Manufacturing Technology, B19, 585
(1996).

10. K. Nawa, M. Ohkita, Y. Sone, and H. Kano, Circuit Technol., 9, 490 (1994)

11. Daicel-Hulls, unpublished data (1997). 